\title{
MÍDIA E EDUCAÇÃO DA MULHER: UMA DISCUSSÃO TEÓRICA SOBRE MODOS DE ENUNCIAR O FEMININO NA TV
}

\author{
ROSA MARIA BUENO FISCHER
}

\begin{abstract}
Resumo: Neste trabalho discutem-se os conceitos de poder, subjetivação e (a)normalidade, de Michel Foucault, bem como os conceitos de cultura e diferença propostos por Homi Bhabha, em relação à temática da enunciaçâo do feminino Conforme a psicanalista Maria Rita Kehl. Tal discussấo é feita no sentido de expor a fundamentaçáo de uma pesquisa em andamento sobre a subjetividade feminina na mídia televisiva, a qual dá continuidade a investigações anteriores, cujos resultados são também brevemente comentádos. O que está em jogo é uma descrição de como se constrói um discurso sobre as mulheres em diferentes produtos televisivos, atentando para os vazios do simbólico em reldção ao feminino. Este, conforme Kehl, tanto para os homens como para as mulheres, "constitui a dimensão maldifa na nossa cultura", já que as mulheres estariam historicamente numa posiçáo em que o sujeîto é sempre o outro: ou o pai, ou a mãe fálica ou o parceiro.
\end{abstract}

Palovras-chave: enunciação, mídia, mulher, dispositivo pedagógico, discurso.

Neste artigo,' discuto algumas questões teóricas a respeito de uma investigação em curso, intitulada "Subjetividade feminina e diferença no dispositivo pedagógico da mídia." Tais questões são tratadas a partir de alguns conceitos-chave de três autores principais: Michel Foucault e os conceitos de poder, subjetivação e (a)normalidade, Homi Bhabha e a discussão sobre diferença e cultura, e Maria Rita Kehl, sobre o problema da enunciação do feminino. Ao final, são apresentados alguns breves exemplos de análises feitas, com o propósito de mostrar a produtividade de articular tais conceitos nas investigações que relacionam mídia, educação e estudos de gênero.

\footnotetext{
1 Este artigo reproduz alguns trechos do trabalho intitulado "Subjetividade feminina e diferença na mídia televisiva", apresentado no X COMPÓs - $10^{\circ}$ Encontro Anual da Associação dos Programas de Pós-Graduação em Comunicação, realizado em Brasília (DF), em maio/junho de 2001.

${ }^{2} \mathrm{Na}$ pesquisa, que conta com apoio do CNPq, estão sendo analisados programas de TV de diferentes gêneros, obedecendo-se ao critério principal de que, de alguma forma, falem da ou para a mulher, de diferentes idades, condições sociais, profissões, etnias, opções sexuais e assim por diante. Assim, selecionamos tanto programas ditos "de mulher", como o Mais Você, da Rede Globo, apresentado por Ana Maria Braga, ou o programa Meninas Veneno, da MTV, ou ainda o seriado Mulher, como talk shows, debates e comerciais de variados anunciantes em que a presença da mulher é nitidamente valorizada. Considerando a escolha de cinco exemplares de dez tipos de produtos (ou gêneros) televisivos, até o final de 2001 teremos analisado um total de 50 materiais
}

ANO $95862 \circ$ SEMESTRE 2001 
A pesquisa sobre subjetividade feminina na mídia dá continuidade a duas investigações anteriores, "Adolescência em discurso: mídia e produção de subjetividade" e "O estatuto pedagógico da mídia", ${ }^{4}$ nas quais evidenciou-se o que vimos chamando "dispositivo pedagógico da mídia", pelo qual os meios de comunicação, de modo particular a televisão, através de diversas estratégias de linguagem, de um lado, têm procurado mostrar-se como locus privilegiado de informação, de "educação" das pessoas; e, de outro, têm procurado captar o telespectador em sua intimidade, produzindo nele, muitas vezes, a possibilidade de se reconhecer em uma série de "verdades" veiculadas nos programas e anúncios publicitários, e até mesmo de se auto-avaliar ou autodecifrar, a partir do constante apelo à exposição da intimidade que, nesse processo, torna-se pública.

Temos visto que não só os programas de entrevistas e de auditório buscam publicizar a intimidade sexual e amorosa das pessoas: também os telejornais e até os chamados programas didáticos e instrucionais, sem falar na produção especificamente ficcional, parecem não sobreviver fora desse ambiente em que a confissão tem sido a "técnica de si" por excelência (conforme escreve Foucault em História da sexualidade l: a vontade de saber). ${ }^{5}$ Trata-se de uma cultura que reforça, de acordo com o psicanalista Jurandir Freire Costa, um tipo de mito racionalista e individualista, segundo o qual será mais autêntico e verdadeiro aquele que tudo expuser publicamente de sua intimidade, como se esse grande lugar público da mídia pudesse mostrar a transparência das verdades individuais e como se essa prática devesse ser considerada não só bastante desejável como necessária, em oposição a outras, entendidas como dissimulação, falsidade, negatividade, hipocrisia. ${ }^{6}$

Ora, os primeiros resultados dessa análise sobre o "dispositivo pedagógico" da mídia indicam que tanto as diversas formas de a TV se fazer pedagógica, educadora, como as de cotidianamente tentar capturar e devolver publicamente a privacidade dos indivíduos não se dão homogeneamente, indiscriminadamente. Apesar da conhecida busca de um "público médio" e, portanto, "total", há sutis e múltiplas maneiras de a mídia falar aos diferenciados públicos, de trazê-los à luz e fazê-los também imagens de consumo cotidiano. Exemplificando: há modos muito específicos de a mídia fazer falar grupos de jovens, adolescentes, crianças, mulheres - e para cada um desses grupos podem-se identificar outras diferenciações, conforme se trate, por exemplo, de mulheres jovens, adultas, idosas, apresentadas como criminosas, prostitutas ou modelos do mundo fashion, mulheres da classe trabalhadora ou do cenário político nacional e assim por diante. Considerando o corpus selecionado na pesquisa sobre "O estatuto pedagógico da mídia" e as categorias de análise referidas às "técnicas de si" e às estratégias de linguagem televisiva, tudo indica que haveria uma predominância da mulher (das mais diferentes faixas de idade e de situações sociais) como protagonista

\footnotetext{
${ }^{3}$ Título da tese de doutorado defendida em 1996 no Programa de Pós-Graduação em Educação da Universidade Federal do Rio Grande do Sul (UFRGS), sob a orientação da professora Céli Regina Jardim Pinto.

${ }^{4}$ Pesquisa realizada de agosto de 1998 a julho de 2000, com apoio do CNPa (Bolsa de Produtividade em Pesquisa), e que contou com a participação das bolsistas de Iniciação Científica Fabiana de Amorim Marcello e Suzana Feldens Schwertner. Ver: FISCHER, 2000a.

${ }^{5}$ FOUCAULT, 1990a.

${ }^{\circ}$ COSTA, 1999.

${ }^{7}$ Analisamos para essa pesquisa 66 produtos televisivos, veiculados nos anos de 1998, 1999 e 2000, entre os quais estão incluídos comerciais, telenovelas, talk shows, programas instrucionais, seriados, programas infantis, telejornais e documentários, entre outros gêneros.
} 
de inúmeras e diferenciadas formas de confissão nas telas da TV, de tal forma que, comparativamente aos homens, elas estão mais presentes como sujeitos falantes, "confessantes" e igualmente como sujeitos a serem formados, educados, ou seja, como sujeitos cada vez mais necessitados de normas e procedimentos para permanentemente "cuidarem de si". ${ }^{8}$

Tendo como ponto de partida, portanto, alguns dos "achados" da pesquisa acima referida (as variadas técnicas de exposição dos indivíduos; os modos de incluir, excluir sujeitos; as múltiplas formas de tratar os "diferentes", especialmente a mulher, e de transformar vidas privadas em espetáculo; e, finalmente, as estratégias de "pedagogizar" os meios de comunicação), continuamos a investigação sobre o estatuto pedagógico da mídia, centrando a atenção em produtos televisivos dirigidos especificamente à mulher ( mulher menina, pré-adolescente, adolescente, jovem, adulta, idosa) ou que a colocam como personagem central ou ainda que discutam de alguma forma sua presença na cultura e na sociedade. Estamos investigando quais as estratégias utilizadas pela mídia para capturar o sujeito mulher em suas mais diversificadas possibilidades de presença (quanto à situação econômica e social, idade, preferências sexuais, etnia, raça, profissão, papel social). Em outras palavras: estamos investigando de que forma se constrói um discurso sobre a mulher na televisão veiculada no Brasil; perguntamonos sobre a mulher e os modos de constituí-la na cultura brasileira contemporânea, considerando-se que a mídia é um lugar privilegiado de criação, reforço e circulação de sentidos, que operam na formação de identidades individuais e sociais, bem como na produção social de inclusões, exclusões e diferenças - temas fundamentais hoje nos mais diversos campos das ciências humanas. Na investigação em curso, selecionamos um conjunto de programas e comerciais de TV em que a mulher é figura proeminente e os submetemos a uma rigorosa análise, cruzando nela elementos de linguagem televisiva e tópicos referentes a técnicas de subjetivação, presentes nesses materiais; ainda, apresentamos alguns desses materiais a um grupo de mulheres, de 18 a 45 anos, estudantes de Pedagogia, em sessões de discussão sobre a presença feminina na TV. Esse conjunto de enunciações (os textos retirados da TV e os textos produzidos pelo grupo de mulheres) constitui o corpus de análise da presente pesquisa.

Aceitamos que a mídia não apenas veicula, mas também constrói discursos e produz significados, identidades e sujeitos - pressuposto que se fundamenta na articulação dos conceitos de poder, saber e sujeito feita por Michel Foucault. Trata-se, na investigação aqui proposta, de problematizar esses mesmos conceitos, a partir de outras perspectivas teóricas voltadas para a complexificação das relações entre sujeito e cultura. Refiro-me aqui especialmente ao conceito de diferença cultural, à oposição normalidade/anormalidade e aos sentidos atribuídos culturalmente ao que seja o "feminino".

\section{Diferença e (a)normalidade}

O crítico indo-britânico Homi Bhabha, em O local da cultura, ${ }^{9}$ faz uma consistente e instigante discussão sobre as oposições entre os conceitos de diversidade e diferença cultural, a partir de uma análise dos atuais movimentos teóricos e políticos de respeito

${ }^{8}$ Todas as expressões relativas às "técnicas de si" (como a da confissão), às normas de "cuidado de si", pertencem a uma terminologia utilizada por Michel Foucault, particularmente nos dois últimos volumes de sua História da sexualidade. FOUCAULT, 1985 e 1990b.

${ }^{9}$ BHABHA, 1998.

ANO $95882 \circ$ SEMESTRE 2001 
às diversidades e ao multiculturalismo. Para Bhabha, o conceito de diferença cultural torna-se crucial na medida em que a diferença aí é vista como uma forma de enunciação da cultura, ou seja, como um processo complexo de significação, através do qual se produzem afirmações e se instituem práticas a respeito das diversas culturas, dos grupos sociais (diferenciados por geração, gênero, etnia, religião, profissão, situação econômica e social), das minorias, enfim, de todos os "diferentes". Estamos falando de práticas discursivas e não-discursivas que, por sua vez, engendram diferenças e discriminações muito concretas no âmbito das instituições. Estamos falando também de práticas profundamente articuladas a processos de dominação e de resistência. ${ }^{10}$

Quando nos propomos a continuar investigando o dispositivo pedagógico da mídia, buscando descrever as estratégias de linguagem que caracterizam a televisão como um local privilegiado de produção de sujeitos, no caso, do sujeito mulher, nas suas múltiplas formas de "aparição" pública (e privada), estamos justamente "tensionando" os conceitos foucaultianos de subjetivação, saber e poder, na medida em que introduzimos nesse conjunto teórico o conceito de diferença cultural que, supomos, tem uma estreita relação com o conceito de anormalidade estudado por Foucault.

O século XIX, como afirma o filósofo francês, tornou-se obcecado pelo medo dos "anormais" - as figuras dos monstros humanos, dos "indivíduos a corrigir" e dos onanistas -, produzindo inúmeras práticas institucionais, discursos e saberes a partir da "exceção jurídico-natural do monstro das multidões, dos incorrigíveis, detidos pelos aparelhos de adestramento e do universal secreto das sexualidades infantis". ${ }^{11}$ Toda essa temática dos homens infames, estudada por Foucault a partir de figuras que perturbam, que combinam o interdito e a impossibilidade de "ser como os outros", que são classificados como perigo e afronta ao "normal", nos diferentes tempos e lugares da história ocidental, parecenos que oferece uma base importante para a compreensão do que vimos hoje discutindo sobre a oposição entre diversidade e diferença cultural. Por quê? Porque, quando acompanhamos todas as lutas em torno do respeito às diferenças - de gênero, de etnia, de raça, de geração, de atividade profissional ou religiosa -, entendemos que de certa forma estamos diante de grupos que se defrontam com o poder e que, nessa medida, constituem-se e são constituídos como identidade social e "normalidade" ou "anormalidade", ao mesmo tempo que são "capturados" cotidianamente nos espaços institucionais, nos discursos que se produzem a partir da própria diferença que se afirma. ${ }^{12}$

$\mathrm{Na}$ realidade, estou aqui questionando um determinado modo de compreender as diferenças como algo indesejável, inadequado, que um dia tornar-se-á normalidade ou então que permanecerá na condição de excluído. Como bem escreve Carlos Skliar, apoiado em Homi Bhabha, há que se compreender as diferenças para além de uma tolerância com as pluralidades ou as diversidades culturais, uma vez que "as diferenças são sempre diferenças" e, como tal, constituem-se fundamentalmente como fato político, são diferenças políticas, diferenças que "não são facilmente permeáveis nem perdem de vista suas próprias fronteiras"; daí que existem independentemente de serem ou não aceitas ou de que algum poder as nomeie como aceitóveis ou "normais". ${ }^{13}$ Elas existem e se

\footnotetext{
${ }^{10}$ Termos como "práticas discursivas e não-discursivas", "dominação" e "resistência" são aqui usados segundo Michel Foucault, particularmente a partir de duas obras básicas: A arqueologia do saber e História da sexualidade I: a vontade de saber. Ver especialmente FOUCAULT, 1986.

"Conforme FOUCAULT, 1997. p. 66.

${ }^{12}$ Sobre o tema foucaultiano da (a)normalidade, ver PINTO, 1999.

${ }^{13}$ Conforme SKLIAR, 1999.
} 
afirmam em lutas muito concretas. Daí que se torna indispensável pensar o conceito de diferença do ponto de vista políitico e social, em relação a tempos e sociedades muito específicas. Assim, por exemplo, num país como o Brasil, com 30 milhões de pessoas em estado de pobreza, é preciso - de acordo com a cientista política Céli Regina Jardim Pinto ${ }^{14}$ - indagar até que ponto a democracia e a afirmação das diferenças têm instrumentos para enfrentar a desigualdade e dar respostas adequadas aos nossos sérios problemas sociais. Lutar pela afirmação das diferenças, então, seria uma questão supérflua? Em que medida as lutas de grupos "diferentes" como o das mulheres, dos gays, dos idosos, dos negros, dos surdos podem ser pensadas em relação a outros diferentes, como os sem-terra, que na verdade lutam não para permanecerem (ou serem reconhecidos como) sem-terra, mas exatamente para terem direito à terra? Para a autora, tais indagações são indispensáveis, no sentido de nossa compreensão avançar para além de um relativismo acolhedor de toda e qualquer diferença e de analisarmos "estas novas identidades no limite da teoria da democracia, entendendo que diferenças não são naturais, que se constituem em um campo de luta e que (sempre) envolvem exclusões". ${ }^{15}$

O mais interessante nesse posicionamento da autora, no que concerne ao nosso estudo sobre mídia e enunciação da mulher no Brasil, é justamente a discussão do tema da diferença como diretamente relacionado não só a questões de injustiça social e econômica, mas também a questões de injustiça cultural, a "padrões sociais de representação, interpretação e comunicação". ${ }^{16}$ Citando a estudiosa Nancy Fraser, o texto de Céli Pinto refere que, se há injustiça cultural em relação a determinados grupos, há que se lutar por algum tipo de mudança simbólica e cultural. ${ }^{17}$ Ou seja, na ordem do simbólico o diferente poderá ser construído como anormalidade, como diferença a ser excluída ou normalizada; ou então, poderá ser "dito" como diferença a ser reconhecida, muitas vezes até (como no caso dos sem-terra), construída para além da esfera pública liberal, no âmbito do "contra-público" - a única forma de essa diferença atingir um espaço de enunciação e reconhecimento. ${ }^{18}$

Neste texto, chamo a atenção exatamente para as estratégias, nos espaços da mídia, de se definir ou estabelecer quem e como são os diferentes - através de enunciados que afirmam "o que são" e "o que não são", por exemplo, os adolescentes brasileiros, os drogados, as modelos publicitárias, as mulheres trabalhadoras das grandes cidades, os "símbolos sexuais" do momento, a dona-de-casa, a empregada doméstica, a professora primária, entre tantos outros construídos muitas vezes como "sujeitos infames". Tais estratégias não se separam de um processo de "enunciação da cultura", como afirma Homi Bhabha, e como tal devem ser pensadas. Ou seja, considerando que não haveria conceitos universais, como por exemplo os de mulher prostituta, de adolescência drogada, de sexualidade jovem ou madura, enfim, de anormalidade, o estudo reitera que há, sim, discursos construídos conflituosa e dinamicamente no interior de relações muito concretas de poder, sobre os vários tipos de diferenças sociais e culturais. Parafraseando Foucault, ${ }^{19}$ diria que estudar as formas pelas quais as figuras e os processos "obscuros" (ou diferentes) são tratados na cultura é uma maneira de desnaturalizar

${ }_{14}$ PINTO, 2001.

${ }^{15}$ PINTO, 2001, p. 8.

${ }^{16}$ PINTO, 2001, p. 9.

${ }_{17}^{17}$ PINTO, 2001, p. 9.

${ }_{18}$ PINTO, 2001, p. 14.

${ }^{19}$ FOUCAULT, 1994, p. 777 e seguintes.

ANO $959022^{\circ}$ SEMESTRE 2001 
aquilo que já se tornou corriqueiro e, por isso, talvez esquecido; é retirar essas figuras e processos de sua paisagem habitual e olhar de frente para eles, esses grupos que um dia foram infames, escandalizaram a sociedade e que foram sendo transformados em grandes universais ("os adolescentes são assim", "as mulheres agem deste modo", "as crianças gostam disso", "Os filhos querem isto dos pais", e assim por diante). Trata-se, através de um longo e rigoroso processo de descrição e análise, de mostrar as "coisas ditas" na cultura como produto de determinadas mudanças históricas muito precisas. "Todas as minhas análises - diz Foucault - rejeitam a idéia de necessidades universais na existência humana. Elas sublinham o caráter arbitrário das instituições e nos mostram o espaço de liberdade de que ainda dispomos, quais são as mudanças que ainda podemos empreender". ${ }^{20}$

\section{Femininos construídos}

Considero que - fundamentada em vários estudiosos que têm pensado a questão de gênero e, particularmente, a emergência do discurso feminino/feminista nas últimas décadas - uma série de universais a respeito da mulher, sobre maternidade, relação com o homem, educação dos filhos, adolescência feminina, vida doméstica, sexualidade, afetividade, trabalho, aptidão física, cuidado com o corpo, idade, desejo, etc., têm sido exaustivamente investigados, ${ }^{21}$ na sua emergência histórica, e questionados, do ponto de vista político, por inúmeros movimentos sociais em diferentes países. Neste trabalho, a idéia é justamente descrever que formas de feminilidade são reforçadas, imaginadas, dinamizadas, polemizadas, enfim, construídas na cultura, através de produtos televisivos, que participam de uma espécie de organização dos ideais de cada gênero, através de um conjunto de representações históricas sobre a mulher no Ocidente. Como escreve a psicanalista Maria Rita Kehl, em Des/ocamentos do feminino, somos herdeiros de discursos que, historicamente, definiram uma "natureza feminina" eterna e universal. Analisando as origens do modo de vida burguês na segunda metade do século XIX em relação à mulher, e a respectiva emergência de produções no campo da literatura, a autora afirma:

O que é específico da mulher, em sua posição tanto subjetiva quanto social, é a dificuldade que enfrenta em deixar de ser objeto de uma produção discursiva muito consistente, a partir da qual foi sendo estabelecida a verdade sobre sua "natureza"', sem que tivesse consciência de que aquela era a verdade do desejo de alguns homens - sujeitos dos discursos médico e filosófico que constituem a subjetividade moderna - e não a verdade "da mulher". Por fim, a esta produção simbólica vai-se contrapondo uma produção literária voltada ao público feminino, que tenta dar uma resposta imaginária aos anseios reprimidos de grande parte das mulheres das classes médias: anseios de viver a grande "aventura burguesa", para além do papel honroso que Ihes era concedido, de mãe virtuosa e Rainha do Lar. ${ }^{22}$

Para Maria Rita Kehl, em rigor, "a única diferença entre um homem e uma mulher é que a mulher é também mulher"; a partir daí, não haveria necessidade de "um lugar para A mulher n'O discurso", pois este jamais é uno e completo e as mulheres já se

\footnotetext{
${ }^{20}$ FOUCAULT, 1994, p. 778-779. (Tradução minha.)

${ }^{21}$ Refiro-me aqui a alguns estudos de autoras que estão sendo utilizados nesta pesquisa, além de Kehl e outras citadas ao longo desta proposta: BUTLER, 1989; PINTO, 1994, p. 67-78; LOURO, 1997; ELLSWORTH, 1997; PERROT, 1988.

${ }^{22}$ KEHL, 1998. p. 15-16.
} 
encontram nele como sujeitos e simultaneamente como objetos. ${ }^{23}$ A partir de Lacan, a autora afirma que, na condição de seres de linguagem, habitantes do simbólico, sujeitos do Verbo, as mulheres necessariamente não apenas espelham ou repetem 0 discurso do Outro; ${ }^{24}$ a aposta de Kehl (no caso, em relação à prática psicanalítica) é o investimento não apenas na escuta do que traumaticamente foi recalcado, mas também na escuta do emergente, "do que ainda não foi dito e procura uma formulação, que cada sujeito tem a dizer a partir de sua experiência pessoal e intransferível". ${ }^{25}$ Ou seja, para o bem ou para o mal, sempre há vazios no simbólico, e é essa justamente a condição para que, por um lado, as sociedades mantenham os universais que interessam a uma determinada forma de organização social ou, por outro lado, para que seja possível pensar em novas formas de "intervenção significante no campo do Outro". ${ }^{26}$

Tais considerações sobre o feminino, da psicanalista Maria Rita Kehl, aliadas à discussão sobre normalidade e anormalidade, feita por Foucault, bem como ao debate empreendido por Bhabha sobre diversidade e diferença cultural, constituem as bases teóricas que sustentam a discussão que relaciona a análise dos discursos da mídia (no caso, sobre a subjetividade feminina), as estratégias de linguagem da televisão e o dispositivo pedagógico identificado nesse local da cultura, na busca de responder como se constrói um discurso sobre as mulheres em diferentes produtos televisivos, atentando para os vazios do simbólico (referido acima) em relação ao feminino. Este, conforme Kehl, tanto para os homens como para as mulheres, "constitui a dimensão maldita na nossa cultura", já que as mulheres estariam historicamente numa posição em que o sujeito é sempre o outro: ou o pai, ou a mãe fálica ou o parceiro. ${ }^{27}$

Tal condição de "diferença", "anormalidade" ou "maldição" feminina tem recebido os tratamentos mais variados ao longo da história da cultura ocidental. Na mídia de nossos dias, os modos como se constroem representações da afetividade, do corpo, da sexualidade da mulher de todas as faixas de idade e de todas as condições sociais indicam uma tensão entre as inúmeras conquistas das lutas feministas e aqueles universais que, entre outras posições, colocam a mulher entre a falta e a sedução, conforme já assinalei em trabalhos anteriores sobre mídia e adolescência ${ }^{28}$ De acordo com Foucault, há uma íntima relação entre poder e subjetividade, entre poder e sexualidade e, diríamos nós, entre poder e constituição de gênero. Num tempo como este, em que se elege o corpo como o lugar de todas as identidades, não há como ignorar que a histórica desigualdade nas relações entre homens e mulheres constitui profundamente não só o corpo feminino como também as identidades de gênero.

Mesmo que Foucault tenha sido criticado por negar o caráter de gênero das técnicas disciplinares, por referir-se a "técnicas de si" ligadas a um sujeito dessexualizado e genérico, como escreve Rosi Braidotti, apud Lois Mcnay, ${ }^{29}$ não haveria incoerência em associar os referenciais teóricos aqui discutidos, já que mesmo estudiosas feministas reconhecem que a teoria do corpo, tal como foi formulada por Foucault em seus três volumes de História da sexualidade, teria resultado em produtivas discussões em torno

${ }^{23}$ KEHL, 1998, p. 328-329.

${ }^{24} \mathrm{KEHL}, 1998$, p. 329.

${ }^{25} \mathrm{KEHL}, 1998$, p. 329-330.

${ }^{26} \mathrm{KEHL}, 1998$, p. 329.

${ }^{27} \mathrm{KEHL}, 1998$, p. 330.

${ }^{28}$ Refiro-me aqui à tese de doutorado, já citada, em que analisei programas de televisão, revistas e jornais, de modo especial aqueles destinados ao público feminino adolescente. FISCHER, 1996.

${ }^{29}$ MCNAY, 1994, p. 11.

ANO $95922^{\circ}$ SEMESTRE 2001 
das tecnologias disciplinares de subjugação da mulher, desenvolvidas e multiplicadas desde o início do último século e mais intensamente nas últimas décadas. A descrição das tiranias do complexo moda-beleza, que continuamente produzem formas patológicas de subjetividade para a mulher de nosso tempo, por exemplo, fundamentase inteiramente em Foucault ${ }^{30} e$, de certa forma, o ultrapassa, já que coloca em evidência - corpo feminino e a inscrição, nele, das lutas de poder entre homens e mulheres, conforme escrevem Sandra Bartky e Susan Bordo, apud Jana Sawiki. ${ }^{31}$

Dialogamos aqui permanentemente com vários trabalhos dos estudos feministas, produzidos sobretudo a partir dos anos 80 . Neles, todo o investimento que as diferentes sociedades fizeram sobre as mulheres, amarrando-as a seus corpos, como "naturalmente" deficientes, em falta, doentes, frágeis - além de tantas outras qualificações justificadas em nome de uma concretude biológica - é investigado a partir de categorias centrais como a de gênero, pela qual é possível distinguir o corpo sexuado e o gênero culturalmente construído e, sobretudo, expor as cristalizadas, universalizadas e naturalizadas relações de poder entre os sexos.

\section{Subjetivação e poderes no discurso da mídia}

Talvez seja importante, mesmo que resumidamente, retomar aqui os conceitos foucaultianos de poder, discurso e subjetivação, para depois expormos em que medida eles se relacionam com os outros conceitos aqui citados, especialmente $o$ de diferença cultural. Falar de sujeito, para Foucault, é falar de modos de subjetivação. Suas pesquisas, em sua maior parte, segundo ele mesmo, sempre estiveram interessadas em indagar sobre o sujeito, mais especificamente sobre como se instituiu um "conhecimento de si", a longa história de fazer do sujeito um objeto de conhecimento pelo homem; mais ainda: como esse fato de tornar o sujeito cognoscível foi-se fazendo não só possível como extremamente desejável e até indispensável para nós. ${ }^{32}$ Foi a partir dessas perguntas que o autor teorizou sobre as "tecnologias do eu", as "técnicas de si" - esses "procedimentos presentes em qualquer civilização, e que são propostos ou prescritos aos indivíduos, para fixar sua identidade, mantê-la ou transformá-la, em função de um determinado conjunto de fins, e isso graças a relações de autodomínio sobre si mesmo ou relações de conhecimento de si por si próprio". ${ }^{33}$

Já nessa definição pode-se observar que o problema do sujeito, em Foucault, não se separa do das normas, das prescrições, dos inúmeros rituais das instituições enfim, do problema do poder. E, para Foucault,

O poder deve ser analisado como algo que circula, como algo que só funciona em cadeia. Nunca está localizado aqui ou ali, nunca está nas mãos de alguns, nunca é apropriado como uma riqueza ou um bem. O poder funciona e se exerce em rede. Nas suas malhas os indivíduos não só circulam, mas estão sempre em posição de exercer este poder e de sofrer sua ação: nunca são o alvo inerte ou consentido do poder, são sempre centros de transmissão. Em outros termos, o poder não se aplica aos indivíduos, passa por eles. ${ }^{34}$

\footnotetext{
${ }^{30}$ A discussão que faço sobre Foucault e relações de gênero encontra-se no capítulo 2 e ao longo da análise feita nos capítulos 4 a 7 da tese de doutorado acima referida.

${ }^{31}$ SAWICKI, 1994. p. 291.

${ }^{32}$ FOUCAULT, 1989. p. 133.

${ }^{33}$ FOUCAULT, 1989, p. 134 (Tradução minha.)

${ }^{34}$ FOUCAULT, 1992. p. 183.
} 
Ao mesmo tempo, as relações de poder implicadas na produção social de sujeitos não se separam de um aparato discursivo bastante complexo: ou seja, normas e prescrições são sobretudo linguagem, verbo, significações construídas, sentidos multiplicados em atos muito concretos. Os enunciados de um discurso são sempre históricos e como tal devem ser analisados: são sempre um acontecimento, que nem a língua nem o sentido podem esgotar inteiramente. ${ }^{35}$ Certamente não há enunciado que não esteja apoiado em um conjunto de signos, mas o que importa é a "função" do enunciado, como elemento de uma determinada formação discursiva: ele atravessa as frases, as proposições, as enunciações, permitindo que estes existam.

Assim, enunciados que encontramos em nossa pesquisa, sobre uma mulher permanentemente culpada e em falta, ou sobre alguém que, como escrevemos acima, oscila entre a falta e a sedução, são extraídos a partir da materialidade de enunciações (por exemplo, entrevistas concedidas por uma mulher a um determinado programa de televisão), mas não se confundem com as exatas palavras pronunciadas pela entrevistadora ou pela entrevistada. Eles são descritos como pertencentes a uma determinada formação discursiva (por exemplo, o discurso conservador machista, o discurso do sucesso da beleza física preconizado pela mídia, e assim por diante) e apreendidos em todas as suas especificidades e heterogeneidade, na medida em que se constituem como acontecimentos. A descrição, por exemplo, procura dar conta destas questões: quem pode dizer o que está sendo dito, que posição deve ocupar o sujeito que enuncia, de que lugar ele fala, a que campo dos saberes ele pertence, com que outros enunciados ele se relaciona, e assim por diante.

Para exemplificar esse tipo de análise, vejamos um programa como o Erótica, da MTV. ${ }^{36}$ Ao estudá-lo, procuramos evidenciar vários aspectos da materialidade enunciativa em jogo: desde o cenário em tons de vermelho, o figurino ao mesmo tempo despojado e sexy da apresentadora, as imagens e a sonorização da abertura, os rituais do programa, ${ }^{37}$ o modo com que o grupo de jovens da platéia e de casa (por email ou por telefone) fala de si mesmo e de sua privacidade, até a simplicidade e a total tranqüilidade do médico Jairo Bouer em receber e comentar os detalhes mais diferenciados de experiência sexual do público. Ou seja, consideram-se todos os elementos constituidores da performance da apresentadora e do especialista, da roteirização do programa, da cenografia, e assim por diante, para descrever enunciados sobre uma sexualidade feminina (e masculina) adolescente. Um desses enunciados poderia assim ser narrado: naquele espaço, em que jovens encontram acolhida e esclarecimento, marcam-se claramente na figura dos dois apresentadores - para falar de um elemento apenas - os lugares do homem (o especialista, o médico, o lugar do saber científico) e da mulher (a sensualidade, a beleza, o desejo), reforçados a cada mensagem eletrônica respondida, a cada telefonema atendido ao vivo, sobre as mais diferentes dúvidas adolescentes. Esse enunciado - que remete a um modo de construir a mulher entre a sedução e a falta (a sensualidade é da apresentadora, mas a ela

\footnotetext{
${ }^{35}$ Conforme. FOUCAULT, 1986. p. 32

${ }^{36}$ Programa veiculado todas as quartas-feiras, às $22 \mathrm{~h}$, desde 1998 , sempre com a presença do médico Jairo Bouer e de uma apresentadora de TV, selecionada basicamente por sua capacidade de comunicação com os adolescentes e jovens, por sua sensualidade, beleza e "naturalidade" no trato dos assuntos de sexualidade.

${ }^{37}$ Quando a apresentadora Babi estava na liderança do Erótica, ao chegar ao set de gravação, tirava delicadamente os sapatos, tênis ou sandálias, antes de sentar-se sobre a cama redonda e cheia de almofadas de cetim, num ritual de convite pleno à intimidade entre TV, platéia e telespectadores.
}

ANO 95942 2 SEMESTRE 2001 
faltaria o saber científico, um tipo de poder específico, o lugar de "verdade", "próprio" do homem) - certamente se constrói na íntima relação com um conjunto mais amplo de estratégias através das quais, em nossa sociedade, buscamos cotidianamente dirigirnos ao sujeito individual, indagando, curiosos, sobre o que ele faz com sua sexualidade. Essa colocação do "sexo em discurso", como refere Foucault, estaria relacionada à técnica de subjetivação fundamental: a confissão, a obrigação de se dizer tudo "técnica de si" que existe, se concretiza também em gestos e rituais midiáticos que sublinham muito claramente as divisões entre gêneros, reservando à mulher modos de existência muito específicos.

Ora, esse processo todo mostra-se como plenamente "pedagógico": não só porque, tomando ainda o exemplo do programa Erótica, se busca explícita e didaticamente informar sobre sexo e amor, mas porque há o recurso permanente a toda uma "tecnologia de si", a uma produção de verdade sobre e para o sujeito individual, que "deve" olhar para dentro de si mesmo e julgar-se como sujeito de uma determinada sexualidade e de um determinado gênero. Diríamos, assim, que o propósito educativo de um programa como o Erótica centra-se justamente na exposição dos sujeitos, basicamente na exposição de todos os medos e inseguranças, de todas as dúvidas, pecados e transgressões - que, ao serem publicizados, são tratados no sentido de uma normalização - no sentido foucaultiano deste termo. Outro exemplo, nesse sentido, é o seriado "Mulher", ${ }^{38}$ da TV Globo, em que temos uma rigorosa seleção de cenas através das quais diferentes personagens - homens e mulheres, mas sobretudo estas - têm a sua privacidade "debulhada" diante do grande público. Neste caso, mesmo que se trate de ficção, o bordão é o mesmo; é como se ouvíssemos este apelo: "exponha sua doença, exponha sua dor, exponha seu erro, exponha seu sonho, exponha seu corpo, exponha sua pieguice, exponha, em suma, a sua 'verdade' - que 'nós' (a TV e seus especialistas) acolheremos você, ofereceremos todas as explicações e the devolveremos novas verdades, que logo serão suas". ${ }^{39}$

Já tínhamos assinalado, em pesquisa anterior, ${ }^{40}$ alguns enunciados importantes sobre modos de construção da subjetividade feminina adolescente, visíveis nos textos e imagens da mídia analisados. Estes dizem respeito, por exemplo, à construção de uma adolescência feminina nos seguintes termos: a) sempre haveria uma indissociável ligação entre o fato biológico e a condição de ser mulher; b) a feminilidade seria "dada" por um conjunto de características originadas da condição biológica, como a do 'mistério feminino' (relacionado basicamente à possibilidade de ser mãe), ao mesmo tempo que por uma "necessária" disponibilidade dos corpos da menina e da mulher a se sujeitarem a técnicas disciplinares, cuidados e tratamentos, indispensáveis à conquista amorosa; ${ }^{41}$ c) a mulher-menina, hoje, não abre mão de eventuais lideranças, de

\footnotetext{
${ }^{38}$ Seriado exibido em 1998 pela Rede Globo.

${ }^{39}$ Apresento uma série de exemplos desse modo de analisar produtos televisivos, em que forma e conteúdo não se separam, em FISCHER, 2000b.

${ }^{40}$ Refiro-me à tese de doutorado, citada acima, em que analisamos quatro produtos: o Programa Livre (do SBT, na época apresentado por Serginho Groisman), o seriado Confissões de Adolescente (baseado no diário da atriz Maria Mariana, e veiculado pela TV Cultura de São Paulo), o caderno Folhateen (da Folha de S.Paulo) e a revista Capricho (da Editora Abril).

${ }^{41}$ Esse tópico é exemplarmente tratado num dos episódios da série Confissões de Adolescente, intitulado "Uma mulher moderna", em que a personagem Carol (Déborah Secco) vive sua primeira menstruação e recebe verdadeiras lições da irmã mais velha, Diana (Maria Mariana), sobre o que realmente é "ser mulher, esse mistério", segundo a personagem diz, diretamente relacionado à capacidade de gerar filhos e que nos conferiria um poder bem mais interessante do que o dado tradicionalmente aos homens. Ver: FISCHER, 1996, p. 147 e seguintes.
} 
atividades intelectuais e até esportivas, mas jamais pode descuidar-se do aperfeiçoamento do corpo, ao mesmo tempo que não deve se esquecer da "verdadeira beleza", a chamada beleza interior, o que os estilistas e profissionais do mundo da moda chamam de "personalidade"; d) o discurso da sexualidade adolescente incorpora medos (AIDS), retoma discursos conservadores (elogio da virgindade e do comportamento de "boa-moça", exemplarmente visível em figuras de enorme sucesso e apelo como a cantora teen Sandy, da dupla Sandy e Júnior), jamais deixa de rememorar a associação entre "decência" e "não-desejo", apenas timidamente expõe a discussão de tabus como o do aborto e evidencia um curioso e terrível modo de resistir à ordem de protegerse da gravidez indesejada e de doenças sexualmente transmissíveis: meninas e meninos, por exemplo, expõem na mídia a recusa a usar camisinha, afirmando desejos e prazeres livres, para além da ameaça da morte. Também se pode dizer, quanto à sexualidade feminina adolescente na mídia, que o discurso do prazer faz-se acompanhar sempre do discurso científico, que nomeia, explica em detalhes, justifica sensações vividas pela menina (e que ela comunica à revista feminina ou confessa ao "mundo" no programa de auditório); sobressai aí a figura do especialista homem, de preferência o ginecologista, aquele que receberá, solícito, as dúvidas, os medos e as vergonhas da menina, em relação a seu corpo-mulher.

Diversas posições e formas de subjetividade podem ser entendidas, segundo essa perspectiva, como efeitos de um campo enunciativo. Ou seja, quando analisamos nos produtos televisivos as regularidades, as freqüências, a distribuição dos diferentes elementos das enunciações, a respeito dos vários grupos de mulheres, estamos entendendo que naquele lugar específico há, mais do que indivíduos concretos a falarem, sujeitos sendo constituídos e constituindo-se, uma vez que, como escreve Foucault, o sujeito dos enunciados é um "lugar determinado e vazio", que pode ser ocupado efetivamente por indivíduos diferentes. ${ }^{42}$ Esse "algo a mais" diz respeito justamente ao "ça parle", ao "diz-se" foucaultiano, ao que há de "murmúrio" na contemporaneidade, no caso, sobre o universo feminino e os modos de constituir a mulher. Através dessas figuras (atrizes, personagens, jornalistas mulheres, apresentadoras, entrevistadas), das cenas enunciativas em que mulheres falam e são faladas na mídia, pode-se descrever um pouco dos discursos que nos produzem e que produzimos sobre gênero na sociedade brasileira.

Em nossos estudos, temos procurado justamente colocar em ação os conceitos foucaultianos de discurso e poder, analisando agora a discursividade da mídia sobre a mulher, de modo a descrever os enunciados que vêm sendo criados, divulgados, incentivados, polemizados, rejeitados, amplamente aceitos, reforçados, exatamente na medida em que - nos parece - há um insistente convite a que o universo feminino se exponha cada vez mais intensamente na cultura, particularmente no espaço televisivo. Como já referimos, esse modo de exposição tem suas peculiaridades e precisa ser visto em todas as suas "diferenças".

Nos talk shows, como por exemplo o de Marília Gabriela, ${ }^{43}$ em várias ocasiões acompanhamos a apresentadora tentando "dissecar" a vida de mulheres simples que se tornaram famosas na mídia brasileira, como Carla Perez, Gretchen ou Suzana Alves, a "Tiazinha": o sucesso do programa é tanto maior quanto mais minuciosas forem as falas sobre a vida privada, os "erros" cometidos no passado, a confissão do arrependimento, os percalços da fama na vida cotidiana, a soma de dinheiro

\footnotetext{
42 FOUCAULT, 1986, p. 109.

${ }^{43}$ Refiro-me aqui a programas exibidos entre outubro de 1998 e fevereiro de 1999, pelo SBT.
} 
alcançada, etc. No entanto, para além da quantidade de coisas ditas, importa observar na análise todos aqueles cruzamentos propostos - considerando as diferenças de classe, de situação social, de nível de informação. Assim é que temos na televisão algumas "leis" como esta: das mulheres que, mesmo famosas, um dia foram pobres e detêm um capital cultural e social baixo (conforme nos ensina Bourdieu), pode-se impiedosamente cobrar, como Marília Gabriela o faz (ao entrevistar, por exemplo, a "Tiazinha"), todas as confissões sobre a vida amorosa, sobre eventuais expedientes utilizados para "subir na vida" e assim por diante, ficando claro para o telespectador que se trata de uma mulher das camadas populares que ali está; os gestos captados, sobretudo a expressão oral, a construção das frases, a resposta às vezes embaraçada às perguntas irônicas e agressivas, os olhares inquisidores daquela que detém o controle do discurso e do lugar (a TV) de onde se fala, os tons de voz da entrevistada e da entrevistadora - todo esse conjunto enunciativo expõe, no caso dos exemplos citados, uma mulher de determinada idade, origem social, com este ou aquele capital cultural e econômico, de tal etnia, e assim por diante. E a expõe de uma determinada maneira, a partir de determinadas valorações e julgamentos, irônica e contraditoriamente apresentada como objeto de desejo, ao mesmo tempo que a marcando como um Outro-diferente-demim, classe média intelectualizada; ou seja, um outro a não ser desejado como lugar de chegada ou como modelo de vida. Preenche-se o vazio do simbólico duplamente: marcando a diferença (de classe, de capital cultural, de origem social), simultaneamente a um reforço de outros enunciados liberais clássicos - do sucesso individual, associado, no caso, à beleza e à sensualidade do corpo feminino.

Trata-se, no âmbito de pesquisas como a discutida neste artigo, da descrição de jogos enunciativos a respeito dos inúmeros "diferentes femininos", que não existem única e exclusivamente na TV ou na mídia de modo mais amplo: ou seja, são ditos que circulam culturalmente e que interpelam públicos massivos e ao mesmo tempo distintos, e que adquirem, naquele espaço cultural específico, uma forma particular de existência. São técnicas de marcar esse Outro-mulher, de classificar e de distinguir modos de "realização" do feminino na cultura contemporânea.

\section{Conclusão}

Procurei mostrar, neste artigo, a produtividade de articular alguns conceitos teóricos (normalidade/anormalidade, sujeito, poder e discurso, em Foucault; diferença, em Homi Bhabha; e enunciação do feminino, em Maria Rita Kehl) em investigações recentes sobre mídia e educação, especialmente aquela em que procuramos descrever enunciados sobre a mulher na mídia televisiva. A hipótese que orienta estes estudos é que o dispositivo pedagógico da mídia, especialmente da televisão, produz formas particulares de subjetivação da mulher, colocando em jogo enunciados de vários campos de saber e poder, através de estratégias de linguagem que expõem o "feminino" em suas diferenças - de gênero, geração, etnia, condição econômica, social e cultural -, ao mesmo tempo que o definem como um "diferente" que deve ser tornado público e controlado, numa tensão permanente entre universais de gênero secularmente preservados e rupturas que buscam afirmar-se como resistência.

A partir de estudos como esses, velhas oposições como as que existem entre sujeito e cultura, indivíduo e sociedade, privado e público são mobilizadas, tomam novas formas e sugerem a necessidade de outras investigações e análises, que dêem conta não só de um determinado espaço cultural (a mídia), mas também das próprias formas de enunciar a cultura e as diferenças em nosso tempo e de promover nela 
processos de subjetivação. Buscamos o avanço exatamente na busca de novas interpretações sobre a cultura e sobre os processos pedagógicos mais amplos, que incluem múltiplos e complexos cruzamentos entre o cultural e o individual, o público e o privado, o sociológico e o psicanalítico, neste caso, particularmente no âmbito das relações de gênero. O debate aberto por estudos nessa área, particularmente em relação aos modos de constituir o feminino na cultura, está diretamente relacionado a um debate maior, de ordem política, no sentido de pensarmos efetivamente novas estratégias de "intervenção significante" no que se refere a tantos e tantas construídos como o Outro (ou a Outra), como o excluído, como a infame. Tais estratégias certamente dizem respeito a um esforço em pensar diferente do que pensamos, em imaginar que é possível educar (ou comunicar) sem necessariamente regular plenamente o Outro, num exercício penoso, porém desejável, de construir modos-artistas de existência, "na" diferença.

\section{Referências Bibliográficas}

BHABHA, Homi. O local da cultura. Belo Horizonte: Editora da UFMG, 1998.

BUTLER, Judith. "Foucault and the paradox ob bodily inscriptions". The Journal of Philosophy, Columbia Uninversity, N. York, v. 85, n. 11, p. 601-607, nov. 1989.

COSTA, Jurandir Freire. Razões públicas, emoções privadas. Rio de Janeiro: Rocco, 1999.

ELLSWORTH, Elizabeth. Teaching positions: Difference, Pedagogy and the Power of Address. New York: Teachers College Press, 1997.

FISCHER, Rosa Maria Bueno. Adolescência em discurso: mídia e produção de subjetividade. 1996. 297 p. Tese (Doutorado) - Programa de Pós-Graduação em Educação da UFRGS, Porto Alegre.

. O estatuto pedagógico da mídia. Porto Alegre: FACED/UFRGS, 2000a. (Relatório

final CNPq. Cópia digitada.)

. "Técnicas de si na TV: a mídia se faz pedagógica". Educação Unisinos, São Leopoldo, v. 4, n. 7, p. 111-139, 2000b.

FOUCAULT, Michel. Resumo dos cursos do Collège de France (1970-1982). Rio de Janeiro: Jorge Zahar, 1997. . História da sexualidade III: o cuidado de si. Rio de Janeiro: Graal, 1985. . A arqueologia do saber. Rio de Janeiro: Forense, 1986. . Resumés des cours (1970-1982). Paris: Kulliard, 1989.

. História da sexualidade l: a vontade de saber. Rio de Janeiro: Graal, 1990a. . História da sexualidade Il: o uso dos prazeres. Rio de Janeiro: Graal, 1990b. . Microfísica do poder. Rio de Janeiro: Graal, 1992. . Dits et Écrits IV - 1980-1988. Paris: Gallimard, 1994.

KEHL, Maria Rita. Deslocamentos do feminino. Rio de Janeiro: Imago, 1998. p. 15-16.

LOURO, Guacira Lopes. Gênero, sexualidade e educação: uma perspectiva pósestruturalista. Petrópolis: Vozes, 1997.

MCNAY, Lois. Foucault and Feminism: Power, Gender and the Self. Cambridge: Polity Press, 1994, p. 11.

PERROT, Michele. Os excluídos da história: operários, mulheres e prisioneiros. Rio de Janeiro: Paz e Terra, 1988.

PINTO, Céli Regina Jardim. "Participação (representação?) política da mulher no Brasil: limites e perspectivas". In: SAFFIOTI, Heleieth; MUÑOZ-VARGAS, Mônica. Mulher brasileira é assim. Rio de Janeiro: Rosa dos Tempos; Brasília: Unicef/Nipas, 1994.

ANO $959822^{\circ}$ SEMESTRE 2001 
. Feminismo, desigualdade social e democracia no Brasil (ou o que a teoria política feminista tem a dizer a propósito das questões de desigualdade social e democracia no Brasil). Porto Alegre: 2001. (no prelo.)

SAWICKI, Jana. "Foucault, Feminism, and Questions of Identity". In: GUETTING, Gary. The Cambridge Companion to Foucault. Cambridge: Cambridge University Press, 1994. p. 291.

SKLIAR, Carlos. "A invenção e a exclusão da alteridade 'deficiente' a partir dos significados da normalidade". In: Educação \& Realidade, Porto Alegre: FACED/UFRGS, v. 24, n. 2, p. 22-23, jul./dez.1999.

Media and Woman's Education: A Theoretical Discussion about the Ways to Enunciate the Feminine on Television

Abstract: This paper discusses Foucault's concepts of power, subjectification and (a)normality, as well as Homi Bhabha's concepts of culture and difference, in relation to the question of the feminine enunciation as articulated by the psychoanalyst Maria Rita Kehl. The article assesses how discourses on women are constructed in different televised products, emphasizing the symbolic emptiness/silences of the feminine. According to Kehl, for both men and women this fact is a consequence of "the cursed dimension in our culture," since women have been historically in a position in which the subject is always the other: be it the father, the phallic mother or the partner.

Keywords: enunciation, media, woman, pedagogical device, discourse. 